\title{
Impact of laptop usage on symptoms leading to musculoskeletal disorders
}

\section{Diksha Gautam* and Nisha Chacko}

Department of Home Science, Family Resource Management, Ethelind School of Home Science, Sam Higginbottom Institute of Agriculture, Technology \& Sciences, Allahabad-211007 (Uttar Pradesh), INDIA

*Corresponding author. Email: shiats.diksha@gmail.com

Received: August 27, 2016; Revised received: April 8, 2017; Accepted: August 12, 2017

\begin{abstract}
Due to inherent portability of laptops, users frequently assume inconvenient postures while using them that may lead to discomfort or injury. The study was conducted to evaluate the postures and identify the prevalence of musculoskeletal symptoms in girls using laptops for which 100 college going female students between 18 - 25 years age group were selected through random sampling technique. A self-structured questionnaire was used to assess the laptop usage among adolescents and Rapid Upper Limb Assessment (RULA) was used to assess the posture of students while working with laptop. Standardized Nordic Musculoskeletal Questionnaire (SMSQ) was used to assess the nature and severity of self-rated musculoskeletal symptoms. Results revealed that the maximum respondent's (74\%) posture came under Action level 3 and $26 \%$ respondents comes under Action level 2 which indicated that the posture needed "further investigation and may need change" or "changes needed soon". There was a positive correlation in Normal (0.50), Mild (0.31), Moderate (0.56) and Severe users $(0.60)$ between the posture adopted by the respondents and the incidence of pain in last 12 months and in Normal (0.76), Mild (0.52), Moderate (0.56) and Severe user (0.65) respectively in last 7 days. The Musculoskeletal Symptoms was prominent in various anatomic regions like Neck, Shoulders, Upper back and Lower back, respectively. These symptoms if not addressed at an earlier stage might lead to Musculoskeletal Disorders.
\end{abstract}

Keywords: Laptops, Musculoskeletal symptoms, Posture, Rapid upper limb assessment, Students

\section{INTRODUCTION}

Computers, and especially laptops, have become standard equipment in higher education as the number of universities instituting laptop initiatives continues to grow (Weaver and Nilsson, 2005). A laptop is a portable personal computer commonly used in a variety of settings, including work, education and personal multimedia. It can be expected that laptop computers have become a working norm for students in the new trend of education.

The size and portability of laptops make them powerful, yet practical devices which are easy to handle. Most adolescents now commonly use laptops on a regular basis so they may be considered as heavy users with an increased usage. Because of the inherent portability users frequently assume inconvenient postures and this puts the laptop user in awkward or unhealthy postures that may lead to discomfort or injury (Rafael et.al 2007). If these discomforts and pain persist continuously, it will be a chronic disorder leading to musculoskeletal discomfort and disorders. There is a need to increase the awareness of ergonomics to improve the current practice of laptop's usage and to minimize health problems among students. It is very important to identify the laptop usage and the postures of the students so that the Musculoskeletal Disorder and its consequences can be controlled before it becomes an obsession. Hence this study was an attempt to find out the postures adopted and the prevalence of symptoms leading to Musculoskeletal Disorder in college students.

\section{MATERIALS AND METHODS}

Exploratory research design was adopted for the present study and 'Survey Method' was used for collecting the data. 100 college going girls were randomly chosen between 18 - 25 years of age for this study from various colleges of Allahabad city.

A self structured questionnaire was used to access the laptop usage among college going girls. The questionnaire comprised of questions based on frequency of laptop usage. Rapid Upper Limb Assessment (RULA) developed by McAtamney and Corlett (1993) was used to assess the posture of students working on laptop. Standardized Nordic Musculoskeletal Questionnaire developed by Kuorinka et.al (1987) was implemented on the respondents scoring higher on RULA for assessing the incidence of pain mainly for lower back, neck, shoulder, elbow and wrist/hands.

\section{RESULTS AND DISCUSSION}

The distribution of respondents according to their 
Laptop Usage was determined by self-structured questionnaire and it was found that from the total sample 6 per cent students were using laptop for less than 1 hours, 57 per cent students were using laptop for 1-3 hours, 25 per cent students were using laptop for 3-5 hours and 12 per cent students were using laptop for more than 5 hours (Table 1).

Postural analysis of college going girls: The Table 2 shows the RULA scores of laptop users on the basis of their usage category. The table 2 reveals that 50 percent respondents falling in normal user category 22.8 percent of the respondents falling in mild user category, 32 percent in moderate user category and 16.6 percent in severe user category were to have a RULA score between 3 -4, Action level 2 which indicates that further investigation was needed and their posture may need changes. Whereas, 50 percent in normal, 77.1 percent in mild, 68 percent in moderate and 83.3 percent in severe users category were found to be in Action level 3 which indicates further investigation and changes needed soon. None were found to have an acceptable posture, that is, Action Level 1 (Table 2).

Similar results were found by Oates et al. (1998) where none of the 95 school children in their study were deemed to have acceptable posture (Action Level 1). Research which used RULA to assess the posture of adults during computer use, similarly found no subject to have acceptable posture (Shuval and Donchin, 2005).

Prevalence of musculoskeletal symptoms of college going girls: Table 3 indicates the distribution of respondents on the basis of Nordic pain Questionnaire depending on their laptop usage in the last 12 months. From the data, it can be seen that maximum score of 34 was observed in mild users followed by moderate, severe and normal users. In the Neck, Trunk and lower limb category signifying a higher incidence of pain among the mild users as compared to other users category. In the Arm, Shoulder, Wrist category It was also observed that maximum score of 11 was seen in mild users followed by 9 in moderate users, 6 is severe users experienced more than normal user category. Thus results revealed that the pain in different parts of the body is the not governed by the time of usage but by posture adopted while working on laptop (Table 3 ). Table 3 also indicates the score of respondents on the basis of Nordic pain Questionnaire depending on their laptop usage in the last 7 days. It can be seen from table 3 that maximum score was observed in mild users i.e. 113 followed by moderate (74), severe (27) and normal users (9) in the Neck, Trunk and lower limb category signifying a higher incidence of pain among the mild users as compared to other users category. In the Arm, Shoulder, Wrist category It was also observed that maximum score was seen in mild users (44) followed by 29 in moderate users, 13 in severe users and least by normal user(10) category. Thus results revealed that the pain in different parts of the body is the not governed by the time of usage but how the work is carried out using laptop. It was found that during last 7 days $40 \%$ mild pain in neck experienced by moderate users and 8.7 mild users experienced severe pain in shoulders, $16.6 \%$ mild and moderate pain in wrists experienced by severe users. $50 \%$ moderate pain in upper back experienced by

Table 1. Distribution of respondents according to their Laptop Usage.

\begin{tabular}{clccc}
\hline S. No. & Laptop user category & Time period (in hours) & $\begin{array}{c}\text { Number of } \\
\text { respondents }\end{array}$ & Percentage \\
\hline 1. & Normal users & less than 1 & 6 & $6 \%$ \\
2. & Mild users & $1-3$ hours & 57 & $57 \%$ \\
3. & Moderate users & $3-5$ hours & 25 & $25 \%$ \\
4. & Severe users & More than 5 hours & 12 & $12 \%$ \\
& $\quad$ Total & & 100 & $100 \%$ \\
\hline
\end{tabular}

Table 2. Distribution of respondents on the basis of RULA scores.

\begin{tabular}{|c|c|c|c|c|c|c|c|c|c|}
\hline \multirow{3}{*}{$\begin{array}{l}\text { S. } \\
\text { No. }\end{array}$} & \multirow[t]{3}{*}{ Users category } & \multicolumn{8}{|c|}{ RULA score } \\
\hline & & \multicolumn{2}{|c|}{$\begin{array}{c}\text { Action level } 1 \\
(1 \text { or } 2)\end{array}$} & \multicolumn{2}{|c|}{$\begin{array}{c}\text { Action level } 2 \\
(3 \text { or } 4)\end{array}$} & \multicolumn{2}{|c|}{$\begin{array}{c}\text { Action level } 3 \\
(5 \text { or } 6)\end{array}$} & \multicolumn{2}{|c|}{$\begin{array}{c}\text { Action level } 4 \\
\text { (7) }\end{array}$} \\
\hline & & $\mathbf{F}$ & $(\%)$ & $\mathbf{F}$ & $(\%)$ & $\mathbf{F}$ & $(\%)$ & $\mathbf{F}$ & $(\%)$ \\
\hline 1. & Normal user $(n=6)$ & 0 & 0 & 3 & 50 & 3 & 50 & 0 & 0 \\
\hline 2. & Mild user $(\mathrm{n}=57)$ & 0 & 0 & 13 & 22.8 & 44 & 77.1 & 0 & 0 \\
\hline 3. & Moderate user $(n=25)$ & 0 & 0 & 8 & 32 & 17 & 68 & 0 & 0 \\
\hline 4. & Severe user $(n=12)$ & 0 & 0 & 2 & 16.6 & 10 & 83.3 & 0 & 0 \\
\hline
\end{tabular}


severe users. $28 \%$ moderate pain in lower back experienced by moderate users, $28 \%$ mild pain in hips/ thighs experienced by moderate users (Table 3 ).

This study finds out the prevalence of MSDs in girls in which higher incidence of pain was experienced among the mild users as compared to other user category. The Musculoskeletal Symptoms was prominent in various anatomic regions like Neck, Shoulders, Upper back and Lower back, respectively. This is in accordance with the study conducted by Ismail et.al (2009) who reported MSD pain in one week was also recorded higher at the neck area $(22.7 \%)$ for the 5 th grade as compared to the 2 nd grade $(8.2 \%)$ while computer use in forward neck posture. However, Yanto et.al (2008) also reported most of the $2^{\text {nd }}$ grade school children reported as having higher thigh pain $(>30 \%)$. For the $2^{\text {nd }}$ grade students, the highest reported musculoskeletal pain was the shoulder area $(16.4 \%)$ followed by the neck (14.5\%) and leg (12.7\%).

In this study as the RULA score increasing the incidence of pain (Nordic scores) also increase which signifies that the pain reported by the respondents was due to the different defective postures adopted while using laptop. It is in accordance with Karen et al (2009) also found that frequent assumption of awkward posture was associated with frequent discomfort. Results also revealed that the incidence of pain associated with the awkward postures adopted by users rather than the time spend on laptop. This is in accordance with the study conducted by Karen et al (2009) on college students who reported experiencing frequent musculoskeletal discomfort specifically associated with the activity of using computers. Palm etal (2007) also found that between $10-43 \%$ of the students who had health complaints believed that their symptoms were related to computer use.

It is depicted from table 5 that there is positive correlation between RULA and Nordic score in all the laptop user category during both last 12 months and last 7 days. Statistically it was found that there was significant correlation at 5\% level of significance between RULA posture and Nordic pain score in Normal, Mild, Moderate and Severe users and the correlation values were $0.50,0.31,0.56$ and 0.60 respectively during last 12 months. In case of last 7 days RULA posture and Nordic pain score in Normal, Mild, Moderate and Severe users were significantly correlated at 5\% level of significance and the correlation values were $0.76,0.52,0.56$ and 0.65 respectively.

It is clear from the table that As the RULA score increasing the incidence of pain (Nordic scores) also increases which signifies that the pain reported by the respondents was due to the different incorrect postures adopted by the college girls using laptop.

Indicating that as the RULA score increasing the incidence of pain (Nordic score) also increases which signifies that pain reported by the respondent due to the different prolonged incorrect postures adopted by the respondent using laptop. It is in accordance with the study conducted by Sui et.al (2009), who reported that Female students had higher rates of musculoskeletal discomfort in each of the specified anatomic site than male students. Students who reported musculoskeletal discomfort had high prevalence $(68.3 \%)$ of MSD related to using computer in last 12 months and spent a longer time on computer related activities (Table 5).

In the previous studies it was analysed that females are more prone to the musculoskeletal discomforts due to laptop and computer usage so in this study the females were focused so that they the recommendations can be given for correct postures.

\section{Conclusion}

Current practice of laptop's usage was ergonomically improper. Prolonged usage in faulty posture has created various musculoskeletal problems among college students. It was concluded from the present study that there was a positive correlation between the posture adopted by the respondents and the incidence of pain. The Musculoskeletal Symptoms was prominent in various anatomic regions like Neck, Shoulders, Upper back and Lower back, respectively which clearly correlate to the local physical demands. These symptoms if not addressed at an earlier stage might lead to Musculoskeletal Disorder. There was a

Table 3. Scores of respondents regarding pain usage in last 12 months and last 7 days based on nordic questionnaire.

\begin{tabular}{|c|c|c|c|c|c|c|c|}
\hline \multirow{3}{*}{ S. No. } & \multirow{3}{*}{ User category } & \multicolumn{6}{|c|}{ Areas of body affected } \\
\hline & & \multicolumn{3}{|c|}{ Neck, trunk and lower limb } & \multicolumn{3}{|c|}{ Arm and Wrists } \\
\hline & & $\begin{array}{l}\text { Last } 12 \\
\text { months }\end{array}$ & Last 7 days & Total & $\begin{array}{l}\text { Last } 12 \\
\text { months }\end{array}$ & $\begin{array}{c}\text { Last } 7 \\
\text { days }\end{array}$ & Total \\
\hline 1. & $\begin{array}{l}\text { Normal users } \\
\quad(\mathrm{n}=6)\end{array}$ & 1 & 9 & 1 & 0 & 10 & 19 \\
\hline 2. & $\begin{array}{l}\text { Mild users } \\
\qquad(\mathrm{n}=57)\end{array}$ & 34 & 113 & 45 & 11 & 44 & 157 \\
\hline 3. & $\begin{array}{l}\text { Moderate users } \\
\qquad(\mathrm{n}=25)\end{array}$ & 22 & 74 & 31 & 9 & 29 & 103 \\
\hline 4. & $\begin{array}{l}\text { Severe users } \\
\quad(\mathrm{n}=12)\end{array}$ & 12 & 27 & 18 & 6 & 13 & 40 \\
\hline
\end{tabular}


Diksha Gautam and Nisha Chacko / J. Appl. \& Nat. Sci. 9 (3): 1687 -1690 (2017)

Table 4. Correlation between RULA and NORDIC scores during last 12 months and last 7 days.

\begin{tabular}{clcccccc}
\hline S. No. & User category & \multicolumn{2}{c}{ RULA score } & \multicolumn{2}{c}{ NORDIC score } & \multicolumn{2}{c}{ Correlation (r value) } \\
\cline { 3 - 8 } & & $\begin{array}{c}\text { Last 12 } \\
\text { months }\end{array}$ & $\begin{array}{c}\text { Last 7 } \\
\text { days }\end{array}$ & $\begin{array}{c}\text { Last 12 } \\
\text { months }\end{array}$ & $\begin{array}{c}\text { Last 7 } \\
\text { days }\end{array}$ & $\begin{array}{c}\text { Last 12 } \\
\text { months }\end{array}$ & Last 7 days \\
\hline 1 & Normal users & 28 & 28 & 1 & 19 & $0.50^{*}$ & $0.76^{*}$ \\
2 & Mild users & 285 & 285 & 45 & 157 & $0.31^{*}$ & $0.52^{*}$ \\
3 & Moderate users & 120 & 120 & 31 & 103 & $0.56^{*}$ & $0.56^{*}$ \\
4 & Severe users & 61 & 61 & 18 & 40 & $0.60^{*}$ & $0.65^{*}$ \\
\hline
\end{tabular}

*Significant, level of significance $5 \%$

need to develop the most effective ergonomics strategy to improve the knowledge and practice of ergonomics among students.

\section{REFERENCES}

Ismail, S., Tamrin, S. and Hashim, Z. (2009). The Association between Ergonomic Risk Factors, RULA Score, and Musculoskeletal Pain among School Children: A Preliminary Result. Global Journal of Health Science. 1 (2):73-84

Karen, L., Cooper, N., Carolyn, M., Sommerich and Gary, M. A. (2009). College students and computers: Assessment of usage patterns and musculoskeletal discomfort. Work: A Journal of Prevention, Assessment and Rehabilitation, 32: 285-98.

Kuorinka, I., Jonsson, B., Kilbom, A., Vinterberg, H., Biering-Sorensen, F., Andersson, G. and Jorgensen, K. (1987). Standardized Nordic questionnaires for the analysis of musculoskeletal symptoms. Journal of Applied Ergonomics, 18 (3):233-37.

McAtamney, L. and Corlett, N. (1993). Based on RULA: A survey method for the Investigation of Work related Upper limb Disorders. Journal of Applied Ergonomics. 24 (2):91-99.

Oates, S., Evans, G.W. and Hedge, A. (1998). An anthropometric \& postural risk assessment of children's school computer work environments. Computers in the Schools, 14: 55-63.
Palm, P., Hansson, R. E., Mortimer, M., Palmerud, G., Toomingas, A. and Wigaeus, T. E. (2007). Computer use, neck and upper-extremity symptoms, eyestrain and headache among female and male upper secondary school students. Scandinavian Journal of Work, Environment and Health Supplement, 3:33-41.

Rafael, M. and Tatiana, G. (2007). A survey of ergonomic issues associated with a university laptop program. Journal of Education and Human Development. 1 (2):115.

Siu, D.C., Tse, L.A., Yu, I.T., Griffiths, S.M. (2009). Computer products usage and prevalence of computer related musculoskeletal discomfort among adolescents. Work. 34(4):449-54.

Shuval, K. and Donchin, M. (2005). Prevalence of upper extremity musculoskeletal symptoms and ergonomic risk factors at a Hi-Tech company in Israel. International Journal of Industrial Ergonomics. 35:569 $-558$

Weaver, B. E. and Nilson L. B. (2005). Laptops in class: What are they good for? What can you do with them? New Directions in Teaching and Learning. 101:3-13.

Yanto, Situmorang, E., Herlina, Siringo-ringo, H., Deros, B.M. (2008). Mismatch between school furniture dimensions and student's anthropometry (A Cross-Sectional Study in an Elementary School, Tangerang, Indonesia). Proceedings of the 9th Asia Pacific Industrial Engineering \& Management Systems Conference (APIEM 2008). 